\title{
SEXUAL PRACTICES OF DEAF AND HEARING SECONDARY SCHOOL STUDENTS IN IBADAN, NIGERIA
}

\author{
*A.O. Sangowawa ${ }^{1}$, E.T. Owoaje ${ }^{1}$, **B. Faseru ${ }^{2}$, I.P. Ebong ${ }^{1}$, and B.J. Adekunle ${ }^{1}$ \\ 1. Department of Community Medicine, University College Hospital, Ibadan, Oyo State, Nigeria. \\ 2. Department of Family Medicine, University of Kansas Medical Centre, Kansas City, USA \\ *Currently at the Institute of Child Health, College of Medicine, University of Ibadan, Nigeria \\ **Currently at the Department of Preventive Medicine and Public Health, University of Kansas Medical \\ Centre, USA
}

\section{Correspondence:}

Dr. Sangowawa Adesola O.

Institute of Child Health,

College of Medicine,

University of Ibadan, Nigeria

E-mail address: daisyolu@yahoo.co.uk

Fax: +234-2-2411768

\begin{abstract}
Background: Adolescents and young people with disabilities generally face various forms of discrimination. Inspite of this, they have to deal with similar reproductive health issues encountered by their abled peers. This situation is made worse by misconceptions that they are not sexually active.

Objective: The objective was to compare the sexual practices of the hearing impaired students with their non-hearing impaired counterparts.

Method: A cross-sectional survey was conducted. All consenting deaf students and an equal number of hearing students attending a half way school in Ibadan participated. Four of the hearing students did not complete the survey and their responses were excluded from the final analysis.

Results: A total of 78 deaf students and 74 hearing students with mean ages of 17.1 (S.D. \pm 3.0$)$ and 15.8 (S.D. \pm 1.9 ) years respectively participated. Twenty-six $(33.3 \%)$ deaf and $36(48.6 \%)$ hearing students had ever had sexual intercourse $(p=0.055)$. Median ages at sexual debut were 16 and 14 years for the deaf and hearing students respectively. The number of sexual partners ever had ranged from 1 to 8 among the deaf and 1 to 6 among the hearing students. Four $(15.4 \%)$ deaf and $23(63.9 \%)$ hearing students reported that they used a condom the last time they had sexual intercourse.

Conclusion: The study revealed that hearing-impaired students like their hearing counterparts were sexually active however deaf students were more likely to engage in unsafe sex. There is therefore a pressing need for comprehensive sexuality education for deaf students in the study area.
\end{abstract}

Keywords: Sexual practices, deaf and hearing students, Ibadan

\section{INTRODUCTION}

Adolescence is a period of physical, mental, psychosocial, and sexual development and maturation during which the individual refines sex roles, selfconcept and relationships with persons of one's own and the opposite sex. Sexual and reproductive health issues are important aspects of this developmental process. A study among secondary school students in Jos, Nigeria revealed that $34 \%$ reported ever having had sexual intercourse ${ }^{1}$. Findings from the NDHS, 2003 revealed that $7.9 \%$ of males aged $15-19$ years reported first sex by age 15 while $20.3 \%$ of females aged $15-19$ years reported first sexual intercourse by age $15^{2}$. However, inadequate access of adolescents and young people to sexual health information and services places them at risk for pregnancy and its associated complications, sexually transmitted infections (STI), and HIV/AIDS. ${ }^{3}$ Adolescents and young people often engage in risky sexual behaviour and condom use among them is often quite low. In this study, Araoye and Fakeye reported that among sexually active Nigerian youth, $87 \%$ of males and $78 \%$ of females knew that having sex with a stable partner and using condoms consistently could prevent HIV infection ${ }^{4}$.

The challenges are greater for adolescents and young people with disabilities as they face various forms of discrimination because of their impairments ${ }^{5}$. Unfortunately, there is minimal comprehensive data on adolescents and people with disabilities in Nigeria. Though current figures are not available, the 1991 
National Population Census reported a crude disability rate (CDR) of 0.48 percent. ${ }^{6}$ Deafness was found to be the most prevalent disability among children aged $0-14$ years affecting about $30 \%$ of children. Fifteen percent of the disabled children were estimated to be dumb, 14\% both deaf and dumb, 11\% blind, 8\% crippled, $7 \%$ mentally ill and $10 \%$ had other disabilities. This data was however limited to seven categories deaf, dumb, deaf and dumb, blind, crippled, mentally ill and other disabilities and underestimates the magnitude of the problem ${ }^{6}$. Facilities available for catering for these children are grossly inadequate. Not only do they have less access to education they often face other forms of discrimination and eventually have fewer opportunities for gainful existence than their hearing counterparts ${ }^{5}$. In addition, there are many misconceptions about their sexuality as it is sometimes assumed that persons with disabilities are asexual and consequently do not require education about their sexuality ${ }^{7}$. As a result, inadequate attention is often given to address their reproductive health needs.

These issues call for urgent attention when viewed against the national HIV prevalence rate of $3.1 \%$ among adults aged 15 to 49 years and about 0.8 to $3.3 \%$ among young people aged $15-24$ years $^{8}$. This study was part of a larger study to compare the HIV/ AIDS knowledge, attitudes and sexual practices of hearing impaired students with those of their nondisabled peers. Results of the sexual practices of the two groups of students are reported here.

\section{MATERIALS AND METHODS}

A cross-sectional study was conducted in one of the two government-owned schools admitting both hearing-impaired and non-hearing-impaired students, in Ibadan, Oyo state in 2003. A pilot study on HIV/ AIDS knowledge and attitudes had been conducted among deaf students attending the other governmentowned school for the deaf in $2002^{9}$. Findings of which were used to estimate the minimum sample size required for this current study.

Hearing-impaired students in the study school are allocated to one arm in each class i.e., Junior Secondary (JS) IA, JS IIA, up to Senior Secondary IIIA). In this arm they constitute about a quarter of the total number of students $(45-55)$. All the 78 deaf students in the junior and senior secondary sections of the school who were present at the time of the study were interviewed. The hearing students were first stratified by sex, thereafter, a simple random sample of seventy-eight of them was selected from the same class arms as the deaf students. Seventy-four of the 78 hearing students who were selected completed the survey questionnaire. Permission to conduct the study was obtained from the school authorities and informed consent was obtained from each of the students. Questionnaires were self-administered and three of the school tutors assisted with clarification of questions for the deaf students. The study instrument was adapted from the UNAIDS/UNESCO/WHO Handbook on School Health Education to Prevent AIDS and STD. ${ }^{10} \mathrm{It}$ contained questions on socio-demographic characteristics and sexual practices.

Data was analysed using the Statistical Package for the Social Sciences (SPSS) version 11.0). Frequencies were generated and chi-square test used to test associations between categorical variables. The level of significance was set at $\mathrm{p}<0.05$.

\section{RESULTS}

Socio-demographic characteristics: Seventy-eight deaf students participated, $48(61.5 \%)$ of who were male and $30(38.5 \%)$ female. Seventy-four hearing students - $44(59.5 \%)$ male and $30(40.5 \%)$ female participated. Mean ages were $17.1( \pm 3.0)$ and $15.8( \pm$ 1.9) years for the deaf and hearing students respectively $(\mathrm{t}=3.035 ; \mathrm{p}=0.003)$. The students were mainly from monogamous families (table 1 ).

\begin{tabular}{|c|c|c|}
\hline $\begin{array}{l}\text { Socio-demographic } \\
\text { characteristics }\end{array}$ & $\begin{array}{l}\text { Hearing-impaired }(\mathrm{N}=78) \\
\mathrm{n}(\%)\end{array}$ & $\begin{array}{l}\text { Non-hea ring im paired }(\mathrm{N}=74) \\
\text { n }(\%)\end{array}$ \\
\hline $\begin{array}{ll}\text { Sex } & \\
& \text { M ale } \\
& \text { Fem ale }\end{array}$ & $\begin{array}{l}48(61.5) \\
30(38.5)\end{array}$ & $\begin{array}{l}44(59.5) \\
30(40.5)\end{array}$ \\
\hline $\begin{array}{c}\text { Family type } \\
\text { M on ogamous } \\
\text { Polygamous }\end{array}$ & $\begin{array}{l}45(69.2)^{*} \\
20(30.8)\end{array}$ & $\begin{array}{l}50(68.5)^{* *} \\
23(31.5)\end{array}$ \\
\hline
\end{tabular}

Table 1: Socio-demographic characteristics of respondents 


\section{Sexual practices of respondents}

A higher proportion of hearing students (48.6\%) had ever had sexually intercourse compared with the deaf students $(33.3 \%)$ ( $p=0.055)$. Almost half, $(47.8 \%)$ of the deaf students were aged 17 years and above at first sexual intercourse and median age at sexual debut was 16 years. Among the hearing students, $38.7 \%$ had sexual debut at 14 years; median age at first sexual intercourse was 14 years (table 2).

The number of sexual partners ever had ranged from 1 to 8 among deaf and 1-6 among hearing students. A comparable proportion of deaf, $9(47.4 \%)$ and hearing students, $16(48.5 \%)$ had only had a sexual partner since they became sexually active. In the 3- month period preceding the survey, $18(81.8 \%)$ of deaf and $18(75 \%)$ of hearing students respectively reported having had only one sexual partner). Only 4 $(17.4 \%)$ deaf compared with $8(22.9 \%)$ hearing students claimed they used alcohol or drugs before they had sexual intercourse at their last sexual act $($ Fisher's exact $=0.746)($ Table 2$)$.

On the methods of preventing pregnancy used at the last sexual act, $17(77.3 \%)$ of deaf students said they did not use any method to prevent pregnancy; only 4 $(18.2 \%)$ mentioned that they used a condom. On the contrary, $23(67.6 \%)$ of hearing students used a condom. More than $70 \%$ of deaf students compared with less than $20 \%$ of hearing students reported that

\begin{tabular}{|l|l|l|l|l|}
\hline Sexual practices & $\begin{array}{l}\text { Deaf } \\
\text { students } \\
\text { n (\%) }\end{array}$ & $\begin{array}{l}\text { Hearing } \\
\text { students } \\
\text { n (\%) }\end{array}$ & Statistic \\
p-value
\end{tabular}

Table 2: Sexual practices of deaf and hearing students 
they had ever been pregnant or gotten someone pregnant.

Socio-demographic and other variables associated with respondents sexual habits

Among both deaf and hearing students, more males than females and more of those aged 15-17 years had ever had sex. This was not statistically significant among deaf students $p=0.622$, though statistically significant among the hearing students $(p=0.040)$ (Table 3). More deaf students from polygamous homes had ever had sex, $7(35.0 \%)$ compared to those from monogamous homes, 13 (28.9\%), $\mathrm{p}=0.622$ and more senior secondary school students, 15 (37.5\%) also reported ever having had sex compared to those in junior school, $11(29.7 \%) \mathrm{p}=0.471$. school students in her study indicated having had sex before $^{11}$. Slap et al. also reported that about $34 \%$ of the non-hearing impaired secondary school adolescents they interviewed in Jos, Nigeria reported having ever had $\operatorname{sex}^{1}$. Our study found that median age at first sexual intercourse was higher among the deaf (16 years) than hearing students (14 years). Findings from Osowole's study documented that age at sexual initiation among the deaf students concentrated in the 16-22 year age group. ${ }^{11}$

The median number of partners ever had was the same (two) among both deaf and hearing students. Slightly more than half of deaf and hearing students reported having had more than a sexual partner since sexual debut. This is also similar to Slap et al.'s findings

\begin{tabular}{|c|c|c|c|c|}
\hline \multirow{3}{*}{$\begin{array}{l}\text { Socio-demographic factors as sociated } \\
\text { with being sexually active }\end{array}$} & \multicolumn{4}{|c|}{ Ever had sex } \\
\hline & \multicolumn{2}{|c|}{ Deaf students } & \multicolumn{2}{|c|}{ Hearing students } \\
\hline & $\begin{array}{r}\text { Yes } \\
\mathrm{N}(\%)\end{array}$ & $\begin{array}{r}\text { No } \\
\text { n }(\%)\end{array}$ & $\begin{array}{r}\text { Yes } \\
\text { n }(\%) \\
\end{array}$ & $\begin{array}{r}\text { No } \\
\text { n }(\%)\end{array}$ \\
\hline \multirow{4}{*}{$\begin{array}{l}\text { Male } \\
\text { Female }\end{array}$} & $\mathrm{N}=26$ & $\mathrm{n}=52$ & $\mathrm{n}=36$ & $\mathrm{n}=37$ \\
\hline & $17(35.4)$ & $31(64.6)$ & $26(59.1)$ & $18(40.9)$ \\
\hline & $9(30.0)$ & $21(70.0)$ & $10(34.5)$ & $19(65.5)$ \\
\hline & \multicolumn{2}{|c|}{$\mathrm{X}^{2}=0.244, \mathrm{p}=0.622$} & \multicolumn{2}{|c|}{$\chi^{2}=4.235, p=0.040$} \\
\hline \multirow{5}{*}{$\begin{array}{l}\text { Age group (years) } \\
10-14 \text { (early adolescence) } \\
15-17 \text { (mid adolescence) } \\
=18 \text { (late adolescence) }\end{array}$} & $\mathrm{n}=25$ & $\mathrm{n}=50$ & $\mathrm{n}=36$ & $\mathrm{n}=37$ \\
\hline & $2(11.5)$ & $15(88.2)$ & $6(40.0)$ & $9(60.0)$ \\
\hline & $11(42.3)$ & $15(57.7)$ & $24(52.2)$ & $22(47.8)$ \\
\hline & $12(37.5)$ & $20(62.5)$ & $6(50.0)$ & $6(50.0)$ \\
\hline & \multicolumn{2}{|c|}{$\chi^{2}=4.751, p=0.093$} & \multicolumn{2}{|c|}{$\chi^{2}=0.673, p=0.714$} \\
\hline \multirow{4}{*}{$\begin{array}{c}\text { Family type } \\
\text { Monogamous } \\
\text { Polygamous } \\
\end{array}$} & $\mathrm{n}=20$ & $\mathrm{n}=45$ & $\mathrm{n}=36$ & $\mathrm{n}=37$ \\
\hline & $13(28.9)$ & $32(71.1)$ & $26(52.0)$ & $24(48.0)$ \\
\hline & $7(35.0)$ & $13(65.0)$ & $10(43.5)$ & $13(56.5)$ \\
\hline & \multicolumn{2}{|c|}{$\chi^{2}=0.243, p=0.622$} & \multicolumn{2}{|c|}{$\chi^{2}=0.458, p=0.499$} \\
\hline \multirow{4}{*}{$\begin{array}{l}\text { Secondary School Level } \\
\text { Junior Secondary School } \\
\text { Senior Secondary School }\end{array}$} & & & & \\
\hline & $11(29.7)$ & $26(70.3)$ & $15(50.0)$ & $15(50.0)$ \\
\hline & $15(37.5)$ & $25(62.5)$ & $21(48.8)$ & $22(51.2)$ \\
\hline & \multicolumn{2}{|c|}{$\chi^{2}=0.519, p=0.471$} & \multicolumn{2}{|c|}{$\chi^{2}=0.01, p=0.922$} \\
\hline
\end{tabular}

Table 3: Socio-demographic and other factors associated with being sexually active

\section{DISCUSSION}

The mean age of the deaf students was significantly higher than their hearing counterparts. This indicates that deaf children commence schooling at an older age than hearing children and may be a reflection of their decreased access to formal education ${ }^{5}$.

The study findings revealed contrary to some misconceptions that deaf students are sexually active though a significantly lower proportion of them had ever had sex compared with their hearing counterparts. The proportion of sexually active students (about a third) was similar to findings by Osowole, who reported that $34.9 \%$ of the deaf Junior Secondary among non-hearing impaired adolescents in Jos, Nigeria where more than $50 \%$ of students had ever had more than 1 sexual partner. ${ }^{1}$ A slightly higher proportion of hearing (25\%) compared with about $20 \%$ of deaf students reported having more than one sexual partner in the 3 -month period preceding the study. This is lower than findings from Osowole's study which reported that $11(37.9 \%)$ of deaf had more than two partners at the time the study was conducted. ${ }^{11}$

On the methods used to prevent pregnancy, only 4 $(15.4 \%)$ deaf students compared with 23 (67.6\%) of hearing students in our study reported that they used a 
condom the last time they had sexual intercourse. This is lower than $34.5 \%$ of sexually active deaf students who reportedly used condom in Osowole's study ${ }^{11}$. Akinpelu \& Lawrence also documented that condom use was low among the deaf adolescents they studied ${ }^{12}$. Slap et al. reported that as many as $61.2 \%$ of hearing adolescents said they used condoms or other birth control. This difference might be attributed to reduced access of deaf students to reproductive health knowledge and services. Our study underscores this dearth of knowledge as about a quarter of deaf students compared with $68.9 \%$ of hearing students were aware that condom use could protect a person from STD and HIV. The effects of unsafe sex practices adopted by a good number of the deaf students was evident in this study as more than $70 \%$ of them compared with less than a fifth of hearing students claimed to have ever been pregnant or gotten someone pregnant. This emphasizes the need for reproductive health information to be made accessible to them. Our study did not however explore whether these pregnancies resulted from non-consensual sex considering the fact that people with disabilities are known to be susceptible to sexual and other forms of exploitation.

Findings among the deaf students also showed that more males, more of those from polygamous homes and more of the older students had ever had sex though these were not statistically significant. Slap et al. however reported that a significant proportion of male students, older students and those from polygamous families had ever had sex.

\section{CONCLUSION}

The study confirmed that hearing impaired students like their hearing counterparts were sexually active though age at onset of sexual intercourse was slightly higher than among hearing students. Hearing-impaired students were also more likely to engage in unprotected sex compared with the hearing students. Adolescent health providers should design comprehensive sexuality education including counseling on safer sex practices for students with hearing impairments.

\section{REFERENCES}

1. Slap G.B., Lot L., Huang B., Daniyam C.A., Zink T.M, Succop P.A. Sexual behaviour of adolescents in Nigeria: Cross sectional survey of secondary school students. BMJ January 4 2003; 326 (15). Available: http://bmj.bmjjournals.com/via the INTERNET. Accessed 2008 April.

2. National Population Commission (NPC) [Nigeria] and ORC Macro. Nigeria Demographic and Health Survey 2003. Calverton, Maryland:
National Population Commission and ORC Macro, 2004. 88.

3. Adolescent Reproductive Health in Nigeria. Available: http://www.advocatesforyouth.org/ PUBLICATIONS/factsheet/fsnigeria.pdf via the INTERNET. Accessed 2009 February.

4. Araoye M.O., Fakeye O.O. Sexuality and contraception among Nigerian adolescents and youth. African J Reprod Health 1998; 2(2):142 150.

5. Anthony H., editor. Children's and Women's Rights in Nigeria: A Wake-up Call, Situation Assessment and Analysis 2001. Lagos: UNICEF and the Nigeria National Planning Commission, 2001. $186-189$.

6. 1991 population census of the Federal Republic of Nigeria: analytical report at the national level. Abuja [Nigeria]: National Population Commission April 1998. HA 4731 A4 1991c

7. Basson R. Sexual health of women with disabilities. Canadian Medical Association Journal 1998; 159(4): 359-362.

8. UNAIDS/WHO Epidemiological Fact Sheets on HIV and AIDS, 2008 Update. Available: www.unaids.org via the INTERNET. Accessed 2008 July 29.

9. Sangowawa A.O, Owoaje E.T., Faseru B. HIV/AIDS Knowledge and information sources among deaf students in a half-way school in Ibadan, Nigeria. XV International AIDS Conference; 2004; Bangkok, Thailand. Medimond International Proceedings; 2004. 195 -200 .

10. UNAIDS/WHO/UNESCO. School health education to prevent AIDS and STD. A resource package for curriculum planners. Geneva: UNAIDS; 1999.

11. Osowole O. At risk sexual behaviour among in-school deaf junior secondary one students in two Nigerian Southwestern cities and its implications for thespread of HIV. XV International AIDS Conference, Bangkok, Thailand, Medimond International Proceedings, 2004; $223-227$.

12. Akinpelu O.F, Lawrence, M.E. Knowledge of contraceptive use among adolescent deaf secondary school students. Journal of Special Education, 8(2): 122 - 129, June, 1998. 